\title{
Pengaruh Pembelajaran Jarak Jauh Bagi Siswa SMA Di Era Covid-19
}

\author{
Heni Jusuf ${ }^{1, *}$, Ahmad Sobari ${ }^{2}$, Mohamad Fathoni ${ }^{1}$ \\ ${ }^{1}$ Fakultas Teknik dan Sains; Universitas Nasional; Jl. Sawo Manila no. 61, Pejaten \\ Pasar Minggu, Jakarta Selatan 12520, telp/fax (021) 7806700/7802718; e-mail: \\ heni.jusuf@civitas.unas.ac.id; fath_devito@yahoo.com \\ 2 Fakultas Hukum; Universitas Nasional; Jl. Sawo Manila no. 61, Pejaten Pasar Minggu, \\ Jakarta Selatan 12520, telp/fax (021) 7806700/7802718; e-mail: \\ sobarinatamiharja@yahoo.co.id \\ * Korespondensi: e-mail: heni.jusuf@civitas.unas.ac.id
}

\begin{abstract}
Covid-19 Era is an era where covid-19 National disaster occurred in Indonesia, with a rapid spread so that the government tried to break the chain of transmission quickly, change lifestyles to be new, because the scope of change is broad ranging from the world of business, culture, social to education and learning. The purpose of the study was to obtain a picture of the implementation of distance learning for high school students of M.H. Thamrin as an effort to suppress the spread of covid-19 in the school environment. In accordance with Circular of Minister of Education and Culture number 4 of 2020 concerning Learning Policy from home, the point is through distance learning, providing a meaningful learning experience, without being burdened by completing curriculum achievements for class improvement or graduation, focused on life skills education including the co-pandemic 19, learning activities and learning tasks from home can vary between students including considering the gap of access or learning facilities at home, evidence or products of learning activities from home are given qualitative and useful feedback from the teacher. All Schools directly implement the Minister of Education's circular without preparation and strategies on how distance learning is carried out, including SMANU M.H. Thamrin who became the subject of this study included students and teachers of M.H. Thamrin. Data is collected by sending online questionnaires through Google form and observations while learning takes place. Data analysis was performed using Milles \& Huberman's interactive model analysis techniques with cycles starting with data collection, data reduction, data presentation, verification and conclusion drawing. The results of the research that have been carried out are: (1) Students, Teachers, Education Personnel and Head of Boarding Schools already have and have used the basic tools needed to participate in distance learning; (2) distance learning that has been done, initially in accordance with normal learning hours, but schools change learning strategies so that distance learning has flexibility in implementation and can motivate to be more active in learning, both independent and group learning; and (3) distance learning allows for social distancing and can minimize students gathering in the school environment so as to reduce the potential for the spread of Covid-19 in the school environment.
\end{abstract}

Keywords: Distance learning, covid-19, SMANU M.H. Thamrin, modernlearner Abstrak
Era Covid-19 adalah suatu era dimana terjadi bencana Nasional covid-19 di Indonesia, dengan
penyebaran yang cepat sehingga pemerintah berusaha memutus rantai penularannya dengan
cepat, mengubah pola hidup menjadi baru, karena cakupan perubahannya luas mulai dari dunia
bisnis, budaya, sosial hingga pendidikan dan pembelajaran. Tujuan dari penelitian untuk
memperoleh gambaran pelaksanaan pembelajaran jarak jauh bagi siswa SMANU M.H. Thamrin
sebagai upaya menekan penyebaran covid-19 di lingkungan sekolah. Sesuai Edaran 
Mendikbud nomor 4 tahun 2020 tentang Kebijakan Belajar dari rumah, yang intinya adalah melalui pembelajaran jarak jauh, memberikan pengalaman belajar yang bermakna, tanpa terbebani tuntuntan capaian kurikulum untuk kenaikan kelas maupun kelulusan, difokuskan pada pendidikan kecakapan hidup antara lain mengenai pandemi covid-19, aktivitas dan tugas pembelajaran belajar dari rumah dapat bervariasi antar siswa termasuk mempertimbangkan kesenjangan akses atau fasilitas belajar di rumah, bukti atau produk aktivitas belajar dari rumah diberi umpan balik yang sifat kualitatif dan berguna dari guru. Semua Sekolah langsung melaksanakan edaran Mendikbud tersebut tanpa persiapan dan strategi bagaimana pembelajaran jarak jauh tersebut dilaksanakan, termasuk SMANU M.H. Thamrin yang menjadi Subjek dalam penelitian ini meliputi siswa dan guru SMANU M.H. Thamrin. Data dikumpulkan dengan mengirimkan kuisioner online melalui google form dan observasi saat pembelajaran berlangsung. Analisis data dilakukan menggunakan teknik analisis model interaktif Milles \& Huberman dengan siklus mulai pengumpulan data, reduksi data, penyajian data, verfikasi dan penarikan kesimpulan. Hasil penelitian yang telah dilakukan yaitu: (1) Siswa, Guru, Tenaga Kependidikan dan Kepala Asrama telah memiliki dan telah menggunakan perangkat dasar yang dibutuhkan untuk mengikuti pembelajaran jarak jauh; (2) pembelajaran jarak jauh yang telah dilakukan, awalnya sesuai dengan jam belajar normal, namun sekolah merubah strategi belajar sehingga pembelajaran jarak jauh memiliki fleksibilitas dalam pelaksanaan dan dapat memotivasi untuk lebih aktif dalam belajar, baik belajar mandiri maupun berkelompok; dan (3) pembelajaran jarak jauh memungkinkan terjadinya social distancing dan dapat meminimalisir siswa berkumpul di lingkungan sekolah sehingga dapat mengurangi potensi penyebaran Covid19 di lingkungan sekolah.

Kata kunci: Pembelajaran jarak jauh, covid-19, SMANU M.H. Thamrin, modernlearner

\section{Pendahuluan}

Era Covid-19 adalah suatu era dimana terjadi bencana Nasional covid-19 di Indonesia, dengan penyebaran yang cepat sehingga pemerintah berusaha memutus rantai penularannya dengan cepat, mengubah pola hidup menjadi baru, karena cakupan perubahannya luas mulai dari dunia bisnis, budaya, sosial hingga pendidikan dan pembelajaran. Sesuai Edaran Mendikbud nomor 4 tahun 2020 (Mendikbud RI, 2020) tentang Kebijakan Belajar dari rumah, yang intinya adalah melalui pembelajaran jarak jauh, memberikan pengalaman belajar yang bermakna, tanpa terbebani tuntuntan capaian kurikulum untuk kenaikan kelas maupun kelulusan, difokuskan pada pendidikan kecakapan hidup antara lain mengenai pendemi covid19, aktivitas dan tugas pembelajaran belajar dari rumah dapat bervariasi antar siswa termasuk mempertimbangkan kesenjangan akses atau fasilitas belajar di rumah, bukti atau produk aktivitas belajar dari rumah diberi umpan balik yang sifat kualitatif dan berguna dari guru.

Semua Sekolah mulai dari TK hingga SMA langsung melaksanakan edaran Mendikbud tersebut tanpa persiapan dan strategi bagaimana pembelajaran jarak jauh tersebut dilaksanakan. Semenjak bulan Maret 2020, siswa SMANU M.H.Thamrin, yaitu sekolah SMA Negeri Unggulan Berasrama di Jakarta Timur, mengeluarkan keputusan bahwa siswa harus meninggalkan asrama untuk jangka waktu yang tidak ditentukan dan proses belajar mengajar menjadi proses Pembelajaran Jarak Jauh. Bagi siswa SMA M.H.Thamrin, belajar mandiri adalah proses pembelajaran yang baru bagi mereka karena selama ini mereka berada diasrama dan selalu bersama-sama. Kegiatan sehari-hari mereka adalah masuk sekolah sesuai dengan jam belajar yaitu pagi hingga sore, malam hari digunakan untuk pendalaman materi 
oleh guru khusus yang didatangkan pihak sekolah, sabtu pelajaran olimpiade oleh guru khusus olimpiade, siswa dibebaskan memilih mata pelajaran olimpiade sesuai dengan peminatannya.

Menurut undang-Undang Sistem Pendidikan Nasional No. 20 Tahun 2003 (Sidiknas, 2003) pembelajaran adalah proses interaksi peserta didik dengan pendidik dan sumber belajar pada suatu lingkungan belajar. Definisi Pembelajaran menurut Atwi Suparman dalam (Suparman, 2014) yaitu pengajar dan peserta didik secara bersamaan menciptakan lingkungan termasuk serangkaian tata nilai dan keyakinan yang dianggap penting untuk menyatukan pandangan tentang realitas kehidupan. Dalam definisi ini, pembelajaran tetap menghadirkan pengajar bersama peserta didik dan berkolaborasi dalam menciptakan kesepakatan tentang apa yang penting agar pada gilirannya mempengaruhi pandangan tentang realitas hidup. Kegiatan pembelajaran adalah suatu rangkaian peristiwa yang mempengaruhi peserta didik sedemikian rupa sehingga perubahan perilaku yang disebut belajar terfasilitasi. Pembelajaran dapat didefinisikan sebagai pengaruh permanen atas perilaku, pengetahuan, dan keterampilan berpikir, yang diperoleh melalui pengalaman.

Dengan dikeluarkannya edaran Mendikbud tersebut, maka membutuhkan kebijakan, strategi dan inovasi baru sehingga menghasilkan suatu model strategik baru yaitu model pembelajaran baru dimana model pembelajaran ini mendorong kearah digitalisasi pendidikan dan mengubah peran dan interaksi antara guru dengan murid dalam pembelajaran. Pembelajaran jarak jauh yang sedang dijalani saat ini tidak sepenuhnya direncanakan dengan baik, karena mendadak dan terpaksa. Semula proses pembelajaran yang sepenuhnya direncanakan untuk dilaksanakan secara tatap muka, namun ditengah-tengah dipaksa untuk diimplementasikan secara jarak jauh. Menurut Atwi Suparman dalam (Suparman, 2014) mengatakan bahwa pembelajaran adalah Setiap upaya yang sistematik dan sengaja untuk menciptakan, agar terjadi kegiatan interaksi edukatif antar dua pihak, yaitu antar warga belajar (peserta didik) dan sumber belajar (pendidik) yang melakukan kegiatan membelajarkan. Definisi tersebut memberikan pemahanan bahwa pembelajaran bukanlah sesuatu yang terjadi seketika itu, melainkan sesuatu yang terlebih dahulu harus direncanakan. Pembelajaran harus tetap dilaksanakan dengan strategi yang mampu meminimalisir kontak fisik antara siswa dengan siswa lain, ataupun antara siswa dengan guru (Firman \& Rahayu, 2020), siswa dengan tenaga kependidikan, siswa dengan petugas dan kepala asrama. Penggunaan teknologi digital memungkinkan siswa dan guru berada di tempat yang berbeda selama proses pembelajaran (Belawati, 2019).

Pemilihan Strategi pembelajaran yang tepat merupakan masalah efektivitas pendidik (Davis, 1991). Hal ini meliputi bagaimana mengelola lima hal, yaitu: pengelolaan waktu, pemilihan apa yang harus disampaikan, mengetahui di mana dan bagaimana menerapkan kekuatan seefektif mungkin, menentukan prioritas yang tepat, dan kemudian menjalin semua itu yang satu dengan yang lain untuk memperoleh keputusan yang efektif.

Dalam mengatasi wabah COVID-19, pemerintah tidak melakukan karantina wilayah (lock down) tetapi menggunakan kebijakan Pembatasan Sosial Berskala Besar (PSBB). Dimulai 
Submitted: 2 Juni 2020; Revised: 23 Juni 2020; Accepted: 14 Juli 2020; Published: 31 Juli 2020

dari ibukota Jakarta, kebijakan ini diikuti oleh wilayah lainnya. Kota Bekasi sebagai wilayah penyangga Jakarta segera menerapkan kebijakan PSBB mengingat wilayah ini berdekatan dengan dikhawatirkan terpengaruh dengan kota Jakarta yang merupakan zona merah dengan hampir separuh kasus COVID-19 ada di wilayah Jakarta. Banyak pihak yang mendukung dan juga kurang setuju dengan PSBB, namun agar perekonomian tetap berjalan dan wabah dapat diatasi, pemerintah tidak mengambil kebijakan karantina wilayah. Untuk mengetahui efektifitas PSBB di kota Bekasi, penelitian ini mencoba menggunakan model SusceptibleInfectedRecoverd (SIR) untuk mengukur laju penyebaran COVID-19. Hasilnya menunjukan adanya laju penurunan kasus terinfeksi dengan beta dan gamma beruturut-turut sebesar 0,071 dan 0,05 dan diprediksi akan berakhir di bulan Juni 2020. (Handayanto \& Herlawati, 2020).

Hal tersebut didukung oleh beberapa riset di seluruh dunia dalam memprediksi puncak sebaran COVID-19 yang beberapa negara sudah masuk dalam masa lonjakan kedua. Untuk wilayah Indonesia beberapa peneliti menggunakan pendekatan soft computing, seperti Support Vector Machine (SVM) regression, dengan beberapa kernel pilihan, antara lain radial basis function, linear and polynomial dengan akurasi yang beragam. Alat bantu dari Google (Google Interactive Notebook) sangat membantu dengan fasilitas kompiler dan servernya (Herlawati, 2020).

Kerucut pengalaman Dale (Dale, 1946) memberikan gambaran bahwa pengalaman belajar yang diperoleh dapat melalui proses perbuatan atau mengalami sendiri apa yang dipelajarinya. Berdasarkan tingkatan kegiatan dalam proses pembelajaran, maka didapatkan pengalaman: melalui lambang kata, pendengaran, gambar visual, video, pameran/peraga, demonstrasi, karyawisata, diskusi, melalui benda-benda tiruan, dan pengalaman secara langsung yang berhubungan dengan benda, kejadian, atau objek yang sebarnya, seperti pada gambar 1 berikut ini.

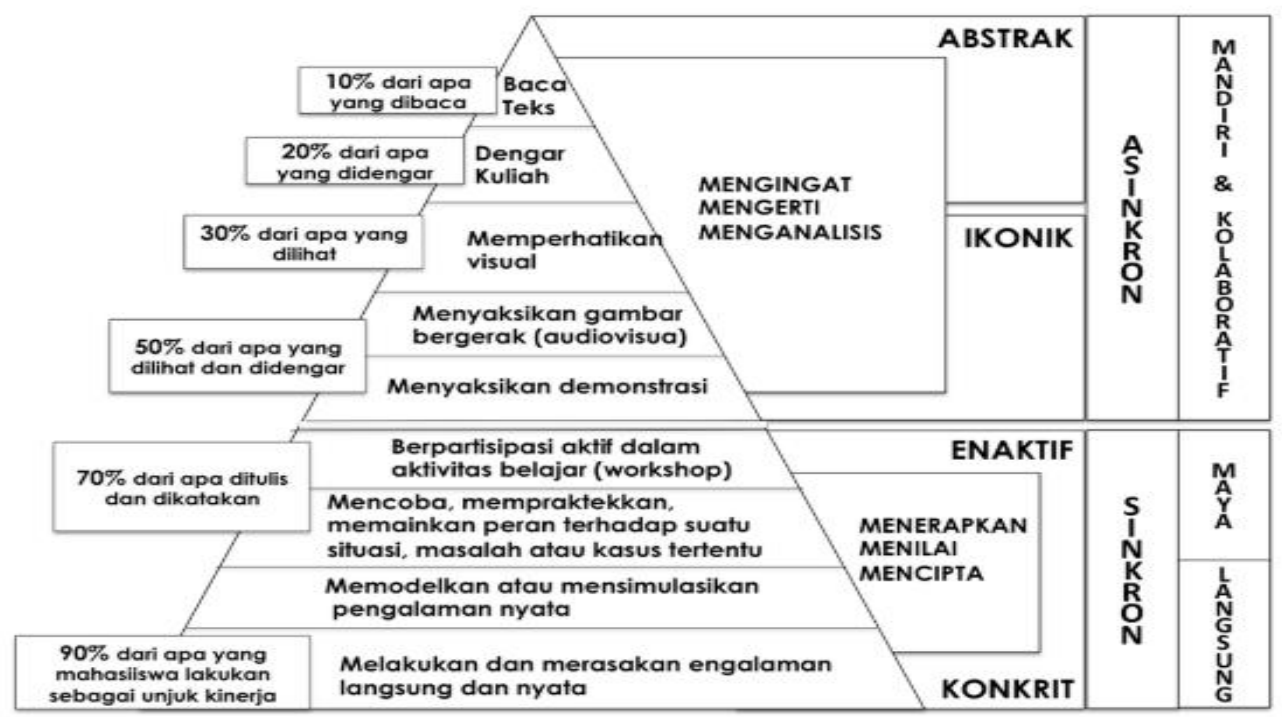

Gambar 1. Kerucut Pengalama Dale (Chaeruman, 2019) 
Menciptakan ruang belajar yang dapat digunakan untuk mendorong siswa agar menjadi siswa yang aktif terlibat, mandiri, belajar seumur hidup adalah tujuan utama pedagogi abad kedua puluh satu dan tantangan untuk desain ruang belajar. Modernlearner adalah sebutan untuk siswa yang belajar dari siapa saja, kapan saja dan dimana saja. Intinya di sini adalah bahwa ada hubungan antara pedagogi, teknologi, dan desain ruang belajar.

\section{Metode Penelitian}

Metode penelitian merupakan cara ilmiah untuk mendapatkan data dengan tujuan dan kegunaan tertentu. Penelitian ini adalah jenis penelitian kualitatif yang mempunyai tujuan untuk memperoleh gambaran pembelajaran jarak jauh yang sedang dilaksanakan di SMANU M.H. Thamrin yang berlokasi di Jakarta timur, sebagai salah satu sekolah yang menyelenggarakan pendidikan jarak jauh untuk menekan penyebaran Covid-19 di lingkungan sekolah. Walaupun sekolah ini terisolasi, tidak bisa sembarang orang masuk, namun masih ada pihak luar yang setiap hari datang ke asrama yaitu: 3 kali dalam sehari petugas catering datang untuk menyiapkan makan bagi siswa-siswi yaitu makan pagi, makan siang dan makan malam, petugas laundry yang datang untuk menyerahkan baju bersih dan mengambil baju kotor siswasiswi, petugas Aqua galon yang mengantarkan galon air ke kamar-kamar siswa-siswi, belum lagi beberapa siswa-siswi terkadang berbelanja online atau memesan makanan via online, oleh karena hal tersebut, kepala sekolah memilih untuk mengikuti edaran mendikbud untuk melakukan pembelajaran dari rumah.

Pembelajaran jarak jauh yang dimaksud dalam penelitian ini adalah pembelajaran yang menggunakan media pembelajaran yang dapat diakeses menggunakan layanan internet. Penelitian dilakukan dengan terlebih dahulu mengadakan survei kepada siswa mengenai pelaksanaan pembelajaran jarak jauh. Survei dilaksanakan menggunakan google form yang disebarkan melalui applikasi WhatsApp. Respoden adalah 240 siswa (tiga angkatan). Hasil survei kemudian dikelompokkan kedalam tiga kategori respon siswa: (1) Setuju dengan penerapan pembelajaran jarak jauh; (2) Tidak setuju dengan penerapan pembelajaran jarak jauh; (3) Ragu dengan pelaksanaan pembelajaran jarak jauh.

Subjek penelitian adalah angkatan tahun masuk 2019 yaitu 80 siswa kelas $X$ yang mengikuti pembelajaran jarak jauh, 40 siswa berjenis kelamin laki-laki dan 40 siswa berjenis kelamin perempuan. Pengumpulan data dilakukan melalui observasi media sosial yaitu line angkatan dan whatsapps orang tua siswa adalah: (1) Fasilitas yang dimiliki siswa untuk mendukung pelaksanaan pembelajaran jarak jauh; (2) Tanggapan siswa mengenai efektivitas pembelajaran jarak jauh; (3) Penerapan pembelajaran jarak jauh dalam menekan penyebaran Covid-19.

Teknik analisis data adalah proses pengumpulan data secara sistematis untuk mempermudah peneliti dalam memperoleh kesimpulan. Analisis data penelitian dilakukan menggunakan model analisis Milies \& Huberman (Milles \& Huberman, 1992) yang terdiri dari 4 
Submitted: 2 Juni 2020; Revised: 23 Juni 2020; Accepted: 14 Juli 2020; Published: 31 Juli 2020

(empat) tahapan, yaitu pengumpulan data, reduksi data, penyajian data, serta penarikan/verifikasi kesimpulan.

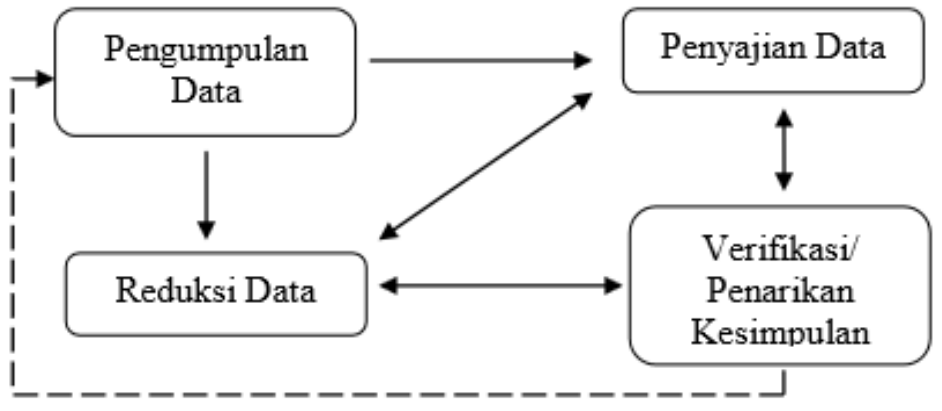

Gambar 2. Model Analisis data Interaktif Miles dan Huberman

Merujuk gambar 2 model analisis data interaktif, secara umum analisis data yang dilakukan dalam penelitian terdiri dari 4 (emapat) tahapan berikut: (1) mencatat semua temuan yang terjadi melalui pengamatan, wawancara dan dokumentasi; (2) mereduksi atau memisahkan data yang dianggap penting dan tidak penting; (3) mendeskripsikan data yang telah dipisahkan sesuai tujuan penelitian; dan (4) membuat kesimpulan akhir dalam bentuk laporan hasil penelitian

\section{Hasil dan Pembahasan}

Kebutuhan adalah kesenjangan antara kondisi yang seharusnya dengan kondisi yang ada saat ini. dengan kata lain apabila terjadi gap antara apa yang seharusnya dimiliki dengan apa yang telah dimiliki maka di sini terdapat suatu kebutuhan. Apabila kebutuhan ini menjadi prioritas untuk segera diatasi, maka akan muncul apa yang disebut dengan masalah. Apabila pembelajaran yang seharusnya dilakukan adalah pembelajaran tatap muka, namun karena kondisi yang mengharuskan pembelajaran diubah secara mendadak menjadi pembelajaran online, maka dapat dikatakan proses pembelajaran tersebut memiliki kebutuhan. Dengan kata lain, apa yang disebut dengan pembelajaran adalah suatu proses menentukan kesenjangan antara apa yang seharusnya. (kondisi ideal atau standar) dengan apa yang terjadi secara nyata (kondisi riil). Hasil penelitian didapat yaitu:

1. Siswa, Guru, Tenaga Pendidik dan Kepala Asrama telah memiliki dan terbiasa menggunakanFasilitas untuk pembelajaran Jarak Jauh.

Selama berada di asrama, siswa, Guru, Tenaga Pendidik dan Kepala Asrama sudah terbiasa belajar dengan menggunakan fasilitas laptop yang terhubung dengan internet baik di ruang kelas, ruang kantor dan di asrama. Karena Kurikulum 3 tahun pembelajaran normal di SMA pada umumnya, di SMANU M.H. Thamrin harus diselesaikan dalam waktu 3 semester alias 1 tahun untuk satu semester. karena semester 4 dan 5 menggunakan kurikulum Cambridge, semester 6 persiapan masuk perguruan tinggi, baik dalam negeri maupun luar negeri. Beberapa penelitian tentang penggunaan perangkat Teknologi Informasi dan komunikasi dalam proses pembelajaran dapat meningkatkan hasil belajar siswa telah 
dilakukan oleh (Brown et al., 2012; Bryant, 2016; Jusuf, 2016; Jusuf et al., 2017; Orey, 2015) hasilnya dengan perangkat teknologi informasi dan komunikasi, siswa dapat belajar dari siapa saja, dari mana saja dan kapan saja, materi pembelajaran dapat diulang-ulang berdasarakan kecepatan belajar siswa. Menurut Bersin (Penfold, 2018) Modernlearner adalah sebutan untuk siswa yang belajar dari siapa saja, kapan saja dan dimana saja.

2. Pembelajaran jarak jauh di rumah

Definisi belajar menurut Abbie Brown menghasilkan dua jenis perubahan yang sangat berbeda berdasarkan aliran behaviorisme dan kognitivisme yaitu The first is a change in behavior; the other is a change in mental representations or associations (Brown et al., 2012). Robert M. Gagne dalam (Luterbach, 2018) mengatakan bahwa belajar merupakan bentuk perubahan tingkah laku, dari sebelum individu berada dalam situasi belajar dan sesudah melakukan proses pembelajaran. Perubahan terjadi akibat adanya suatu pengalaman atau latihan menurut John Dewey dalam (Januszewski \& Molenda, 2008), Albert Bandura dalam (Loon, 2017) menyatakan bahwa lingkungan membentuk perilaku dan perilaku membentuk lingkungan, yaitu proses dimana dunia dan perilaku seseorang saling mempengaruhi.

Awal pembelajaran jarak jauh dilakukan, satu minggu sebelum pelaksanaan Penilaian tengah semester berjalan, siswa dan guru masih dalam penyesuaian dengan metode belajar yang baru. Pembelajaran masih sesuai jadwal pembelajaran tatap muka, yaitu mulai jam 07.00 pagi hingga jam 16.00 sesuai jam belajar, guru membuat forum diskusi di aplikasi whatsapps, materi pembelajaran diambil dari ruang guru berdasarkan topik bahasan yang sesuai. Saat Penilaian tengah semester dilakukan, orang tua wajib men-download aplikasi timestamps, yang digunakan untuk memfoto siswa yang sedang ujian, karena pada aplikasi tersebut dapat memberikan keterangan tentang lokasi dan jam saat foto diambil, sebagai croscek keberadaan siswa dan jam siswa mulai mengerjakan ujian. Ujian dilakukan di rumah masing-masing dengan jadwal seperti ujian tatap muka.

Setelah pelaksanaan penilaian tengah semester selesai, guru dan siswa memulai pembelajaran jarak jauh dengan metode baru, yaitu, satu mata pelajaran, dilaksanakan dalam satu sesi, hal ini membuat guru tidak terbebani dan tidak mengajar berulang. Satu sesi mata pelajaran, diikuti oleh 80 siswa (satu angkatan hanya menerima 80 siswa). Pembelajaran dilakukan menggunakan aplikasi zoom, googlemeet, google classroom, whatsapps, line, dan youtube dengan pemberian tugas beragam, pembelajaran menjadi pembelajaran mandiri yang masih terstruktur dan dalam bimbingan guru, dilaksanakan hingga sore hari, sebelum berbuka puasa, siswa bergantian memberikan kultum melalui aplikasi zoom. Pembelajaran selalu menggunakan aplikasi video conferece dimaksudkan agar para guru dapat melihat siswa dan siswa dapat melihat guru dan teman-temannya. Dalam proses pembelajaran ini, siswa belajar hingga malam hari, untuk mengerjakan tugas-tugas, berdasarkan tugas yang diberikan (sama persis dengan kondisi di asrama, belajar hingga malam). Bentuk penugasan berupa soal-soal yang dapat membuat siswa mengali dan mempelajari lebih mendalam tentang topik bahasan 
Submitted: 2 Juni 2020; Revised: 23 Juni 2020; Accepted: 14 Juli 2020; Published: 31 Juli 2020

pada tugas tesebut. Metode pembelajaran drill and practice dalam taksonomi bloom masuk pada area 4, 5 dan 6 .

3. Efektifitas pembelajaran Jarak Jauh

Pembelajaran jarak jauh yang diberlakukan sebagai usaha untuk mencegah penyebaran Covid-19 dilakukankan menggunakan aplikasi pembelajaran google classroom, aplikasi video conference zoom, google meet dan media social (line dan Whatsapps) yang dapat diakses selama terdapat jaringan internet. Secara umum, siswa merasa kesulitan mengenai pelaksanaan pembelajaran. Melalui pembelajaran secara jarak jauh, guru, kepala asrama memberikan bimbingan dan arahan melalui media sosial dan aplikasi video conference yang dapat diakses di manapun. Orang tua mendapatkan laporan tentang proses pembelajaran setiap hari melalui aplikasi whatsapps dari sekolah

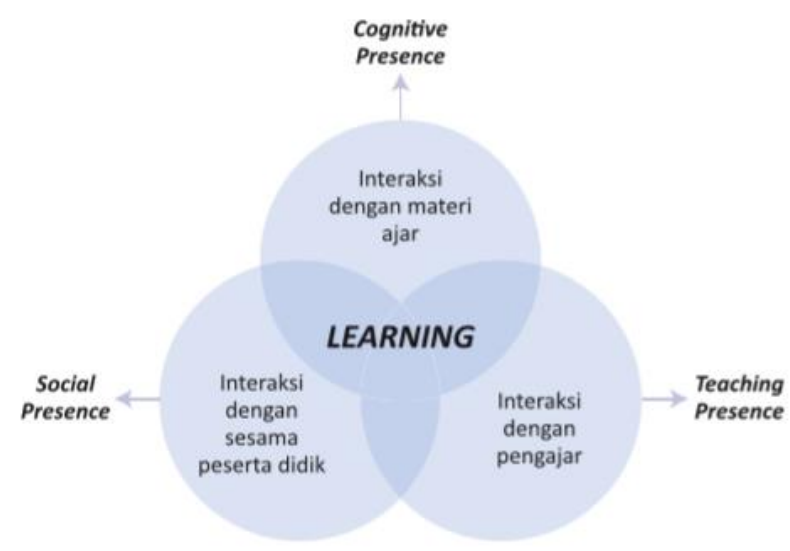

Gambar 3. Interaksi Pembelajaran dari Moore dan teori Community of Inquiry (Belawati, 2019)

Dari gambar terdapat tiga tipe interaksi dalam pembelajaran yang saling mendukung dalam memberikan pengalaman belajar. Saadatmand dalam (Belawati, 2019) menyebutkan bahwa interaksi antar sesama siswa akan menciptakan pengalaman belajar sosial (social Presence), interaksi siswa dengan materi pembelajaran akan menghasilkan pengalaman cognitif (cognitive presence) dan interaksi siswa dengan guru akan menciptakan pengalaman belajar yang terancang secara sistematik (teaching presence). Kata presence diartikan sebagai suatu perasaan keterlibatan aktif siswa dalam proses pembelajaran.

Hasil temuan menarik dalam penelitian ini. Siswa merasa pembelajaran jarak jauh sama dengan pembelajaran tatap muka. Karena aktivitas yang dilakukan sama, seperti yang dilakukan di sekolah, bedanya siswa tidak berada di sekolah dan asrama. Kelemahannya pembelajaran jarak jauh ini kurang dalam hal panduan untuk mengerjakan tugas-tugas dari guru, sehingga siswa melanjutkannya melalui sosial media. Pemakaian kuota internet juga meningkat akibat menggunakan video conferece, sehingga sekolah membuat kebijakan memberikan kuota internet bagi siswa yang membutuhkan diambil dari dana BOS dan kelmahan lainnya adalah ketersediaan PLN, karena pernah saat proses pembelajaran terjadi ada rumah yang listriknya padam, sehingga siswa tidak dapat mengikuti pelajaran. Data 
penelitian juga menunjukkan bahwa siswa tidak kesulitan dalam memahami pelajaran dan mengerjakan tugas yang diberikan secara jarak jauh. Komunikasi dengan guru melalui aplikasi pesan instan mampu memberikan penjelasan kepada siswa tentang materi yang sedang dibahas. Kemampuan guru dalam mengoperasikan perangkat digital sudah baik, siswa memiliki ketersediaan sarana prasarana, Faktor dukungan internal siswa (komitmen, motivasi, kedisiplinan), dan Faktor dukungan lingkungan siswa (tempat belajar dan akses internet).

\section{Kesimpulan}

Sebagai sekolah yang mengikuti surat edaran Mendikbud dalam ranga menekan penyebaran Covid-19, SMANU Mh.Thamrin, yaitu sekolah SMA Negeri Unggulan Berasrama di Jakarta Timur, mengeluarkan keputusan bahwa siswa harus meninggalkan asrama untuk jangka waktu yang tidak ditentukan dan proses belajar mengajar menjadi proses Pembelajaran Jarak Jauh. Melalui penelitian ini dapat disimpulkan bawah siswa, guru, tenaga kependidikdan dan kepala asrama telah memiliki perangkat yang dibutuhkan untuk mengikuti pembelajaran jarak jauh. Meski demikian, terdapat beberapa hal yang harus diperhatikan, termasuk didalamnya ketersediaan layanan internet, biaya tambahan yang harus dikeluarkan oleh siswa dan layanan PLN (Pembangkit Listrik Negara) agar tidak mati saat proses pembelajaran sedang terjadi. Strategi pembelajaran membuat kemandirian belajar dan memotivasi siswa untuk lebih aktif dalam pembelajaran drill and practice. Pelaksanaan pembelajaran jarak jauh memungkinkan siswa untuk mengikuti pembelajaran dari rumah masing-masing. pembelajaran jarak jauh memungkinkan terjadinya social distancing dan dapat meminimalisir siswa berkumpul di lingkungan sekolah sehingga dapat mengurangi potensi penyebaran Covid-19 di lingkungan sekolah. Dengan diterapkannya kebijakan belajar jarak jauh dari sekolah pada beberapa bulan kebelakang, terdapat fenoma baru yang terjadi yaitu kesadaran yang tinggi dari orangtua akan sulitnya menjalankan profesi guru, meningkatnya kesadaran akan pendidikan ke orangtuaan yang selama ini banyak terabaikan, proses pendidikan yang lebih multiliterat, meningkatnya pemahaman guru akan kondisi anak dan keluarganya, peningkatan literasi digital guru, orangtua, dan siswa, guru dan siswa lebih banyak mengekplorasi materi-materi diluar buku paket. Sejauh mana dampak penggunaan teknologi dan metode baru ini berdampak pada mutu pembelajaran masih harus dikaji. Kondisi saat ini pembelajaran diperkaya dengan internet dan blended, teknologi bukan segala-galanya dan belum tentu cocok dengan semua siswa. Pedagogy lebih utama dari pada teknologi

\section{Ucapan Terima Kasih}

Terima kasih ditujukan kepada Wakil Rektor Bidang Penelitian dan Pengabdian Kepada Masyarakat dan Kerjasama Universitas Nasional atas dukungan terhadap penelitian ini.

\section{Daftar Pustaka}

Belawati, T. (2019). Pembelajaran Online (Issue December 2019). 
Submitted: 2 Juni 2020; Revised: 23 Juni 2020; Accepted: 14 Juli 2020; Published: 31 Juli 2020

Brown, A., Green, T., Orey, M., Jones, S. A., \& Branch, R. M. (2012). Educational Media and Technology Yearbook (Vol. 36). https://doi.org/10.1007/978-1-4614-1305-9

Bryant, P. (2016). Learning and Teaching Mathematics. In Learning and Teaching Mathematics. https://doi.org/10.4324/9781315784939

Chaeruman, U. A. (2019). Panduan Memilih dan Menentukan Setting Belajar Dalam Merancang Pembelajaran Blended (Issue April). https://doi.org/10.13140/RG.2.2.29360.00006

Dale, E. (1946). Audio-Visual Methods in Teaching.

Davis, I. K. (1991). Pengelolaan Belajar. Rajawali.

Firman, \& Rahayu, S. (2020). Pembelajaran Online di Tengah Pandemi Covid-19. Indonesian Journal of Educational Science (IJES), 2(2), 81-89. https://doi.org/10.31605/ijes.v2i2.659

Handayanto, R. T., \& Herlawati, H. (2020). Efektifitas Pembatasan Sosial Berskala Besar (PSBB) di Kota Bekasi Dalam Mengatasi COVID-19 dengan Model Susceptible-InfectedRecovered (SIR). Jurnal Kajian Ilmiah, 20(2), 119-124. https://doi.org/10.31599/jki.v20i2.119

Herlawati, H. (2020). COVID-19 Spread Pattern Using Support Vector Regression. PIKSEL: Penelitian IImu Komputer Sistem Embedded and Logic, 8(1), 67-74. https://doi.org/10.33558/piksel.v8i1.2024

Januszewski, A., \& Molenda, M. (2008). Educational Technology : a Definition with Commentary (F. Routledge (ed.)). Routledge.

Jusuf, H. (2016). Penggunaan Gamifikasi dalam Proses Pembelajaran. Jurnal TICOM, 5(1), 16.

Jusuf, H., Azimah, A., \& Firdaus, R. (2017). E-learning for facilitating learning. 2016 International Conference on Informatics and Computing, ICIC 2016, 90-93. https://doi.org/10.1109/IAC.2016.7905695

Loon, M. (2017). Designing and developing digital and blended learning solutions. Kogan Page. Luterbach, K. J. (2018). Designing and Developing Robust Instructional Apps (F. Routledge (ed.)). Taylor and Francis.

Mendikbud RI. (2020). Surat Edaran Nomor 4 Tahun 2020 Tentang Pelaksanaan Kebijakan Pendidikan Dalam Masa Darurat Penyebaran Coronavirus Disease (COVID-19). 1-3.

Milles, \& Huberman. (1992). Analisis data kualitatif. Universitas Indonesia Press.

Orey, M. (2015). Educational media and technology yearbook. Volume 39 / Michael Orey, Robert Maribe Branch, editors (Vol. 39).

Penfold, S. (2018). The Profile of The Modern Leraner: the Trends and Data You Need to Know. 4 September 2018.

Sidiknas, U. (2003). Undang-Undang Sistem Pendidikan Nasional (Issue 1). https://doi.org/10.16309/j.cnki.issn.1007-1776.2003.03.004

Suparman, M. A. (2014). Desain Istruksional Modern (N. I. Sallama (ed.); 4th ed.). Erlangga. 